resuscitation (CPR) model, cardiac arrest of 15 minutes was followed by reperfusion with closed chest cardiopulmonary bypass (CPB). Group $1(n=5)$ received mild hypothermia $\left(33-34^{\circ} \mathrm{C}\right)$, Group $2(\mathbf{n}=5)$ received deep hypothermia $\left(26-37^{\circ} \mathrm{C}\right)$, and the levels of SOD, MDA, NO in plasma and tissues were measured during CPR.

Results: After cardiac arrest of 15 minutes, the concentrations of SOD in the plasma of Group 1 (2615.8 $\pm 57.64 \mathrm{u} / \mathrm{ml})$ was significantly higher than during the prearrest period $(2586.4 \pm 61.78 \mathrm{u} / \mathrm{mi})(p<0.05)$, and for Group $2(2690.5 \pm 35.50 \mathrm{u} / \mathrm{mi})$ also was higher than during the pre-arrest period. The concentration of SOD in plasma at 1 hour of $\mathrm{CPB}$, were lower than pre-arrest $(p<0.05)$ and nearly pre-arrest $(p>0.05)$ at 3 hours of CPB. The levels of MDA and NO were lower than pre-arrest level after cardiac arrest of 15 minutes, at 1 hour, and 3 hours of CPB. There was no difference between the two groups. After 3 hours $\mathrm{CPB}$, the concentrations of SOD in the cerebral tissues in Group $2(1075.6 \pm 11.15 \mathrm{u} / \mathrm{mi})$ was significantly higher than in Group $1(1057.2 \pm 11.80 \mathrm{u} / \mathrm{mi})(p<0.05)$. In the pulmonary tissues, the concentration of SOD in Group $2(690.6 \pm 8.7 \mathrm{u} / \mathrm{mi})$ also was significantly higher than in Group $1(626.67 \pm 23.50 \mathrm{u} / \mathrm{ml})(p<0.01)$, and the levels of MDA $(4.72 \pm 1.5 \mathrm{u} / \mathrm{mi})$ was lower than in Group $1(7.32$ $\pm 1.54 \mathrm{nmol} / \mathrm{g})(p<0.05)$. In the cardiac tissues, the levels of MDA and NO in Group 1 were significantly lower than in Group $2(p<0.05)$.

Conclusions: In resuscitations using closed-chest hypothermia, CPB may decrease free-radical-induced reperfusion injury after cardiac arrest of 15 minutes in dogs. The cerebral and pulmonary reperfusion injury during deep hypothermia CPB was less than during mild hypothermia, whereas the cardiac reperfusion injury during mild hypothermia, CPB was less than during deep hypothermia. Keywords: cardiopulmonary arrest; cardiopulmonary bypass (CPB); cardiopulmonary resuscitation (CPR); free radicals; hypothermia; malondialdehyde (MDA); nitrogen monoxide (NO); reperfusion injury; superoxide dismutase (SOD)

Prebosp Disast Med 2002;17(s2):s77-78

E-mail: pzhuang@zshospital.net or pzhuang@citiz.net

\section{Hospital Disaster Preparedness at a Government- Designated Core Disaster Hospital}

Kiyoshi Ishikawa: Koji Sato; Mitsuki Tanaka; Nami Tojo

Nagoya Daini Red Cross Hospital, Japan

After the Great Hanshin-Awaji earthquake in 1995, the Japanese government designated core disaster hospitals in each prefecture. Nagoya Daini Red Cross Hospital is one of the core hospitals, and should meet the following requirements: (1) have a durable structure; (2) strong lifeline facilities; (3) ample storage of medical supplies and equipment; (4) be prepared to accept many disaster casualties; (5) ability to dispatch rescue squads immediately; and (6) have hospital disaster plans and conduct full disaster drills regularly.

In 2001, a new emergency and critical care center of the hospital was established in order to fulfill the role and responsibility as the core hospital. The structure of the center consists of six stories above-ground and two stories below-ground level. It was constructed in such a way that it would withstand an earthquake of the size of the Great Hanshin-Awaji quake. In the second basement level is the energy center where the life-line facilities are kept. These include electricity and water supplies that can be provided for three days to in-hospital patients, disaster casualties, and hospital staff. The Emergency Outpatient Department on the first floor is large enough to treat many disaster casualties simultaneously.

As for human-related disaster preparedness, disaster relief drills are conducted regularly to encourage the staff to know how to act should a disaster happen. The planning of a disaster relief drill is the most important part of the hospital plan. Disaster preparedness at Nagoya Daini Red Cross Hospital, as a core designated disaster hospital, will be described in this paper.

Keywords: critical care; disaster; drills; earthquake; emergency; hospital; lifelines; preparedness; relief; rescue squads; storage Prehosp Disast Med 2002;17(s2):s78.

\section{Studies On The Prophylactic-Therapeutic Effects of Rhubarb on Lung Injury Caused by Abdominal Infection in Rats}

Professor Jing Bing-Wen; Wang Mo-Qin, Head Nurse Intensive Care Department, Chang Zheng Hospital, Shanghai, Peoples Republic of China

Introduction: Gram-negative sepsis, of which the bioactivity constituent is endotoxin, is one of the most common causes of acute lung injury (ALI) or of acute respiratory distress syndrome (ARDS). Although the control of infection is easily acquired through administration of appropriate antibiotics, the injury to organs, especially lungs, caused by endotoxin released from dead bacteria, is often difficult to treat.

Methods: The cecal ligation and puncture (CLP) in rats utilized to make the model of lung injury with the abdominal infection. Pulmonary vascular permeability, the lung wet-to-dry weight $(\mathrm{W} / \mathrm{D})$ ratio, and the differential cell count both in blood and in bronchoalveolar lavage fluid (BALF) were examined. The concentrations of TNF, IL-8, and PLA2 in plasma, lung tissue, and BALF were measured. The observation of continuous changes of all parameters and the analyses of correlation between all parameters in the blood and in lung tissue were performed to provide a rationale to judge the severity of diseases. Rhubarb was administered upon this animal model in order to prove its prophylactic therapeutic effects on lung injury caused by the abdominal infection in rats.

Results: At the early stage of abdominal infection in rats, the pulmonary vascular permeability and the lung wet-todry weight ratio increase significantly. Intestinal bacterial translocation, and the intake of endotoxin into blood may result in high concentrations of endotoxin in the plasma, lung tissue, and BALF. The concentrations of endotoxin, and/or PLA2 in plasma, and/or BALF may reflect those in lung tissues. The sequestration of activated neutrophils into lungs may lead to a significant increase of TNF, IL-8, and PLA2 in them. The differential cell count in lungs, TNF, and IL- 8 are not of plasma, but of BALF may reflect those in the lung tissues.

Conclusion: Administration of rhubarb may inhibit the 